Western University

Scholarship@Western

Human Environments Analysis Lab (HEAL)

$11-2015$

An evidence-based method for targeting an abusive head trauma prevention media campaign and its evaluation

Tanya Charyk Stewart

Jason A. Gilliland

Neil G. Parry

Douglas D. Fraser

Follow this and additional works at: https://ir.lib.uwo.ca/healpub 


\title{
An evidence-based method for targeting an abusive head trauma prevention media campaign and its evaluation
}

\author{
Tanya Charyk Stewart, MSc, Jason Gilliland, PhD, Neil G. Parry, MD, \\ and Douglas D. Fraser, MD, PhD, London, Ontario, Canada
}

BACKGROUND: A triple-dose abusive head trauma (AHT) prevention program (Period of PURPLE Crying) was implemented. The third dose consisted of an education media campaign. The study objectives were to describe the qualitative and spatial methods developed to target AHT prevention and to evaluate this campaign.

METHODS: A questionnaire on the level of importance of factors, rated on a 7-point Likert scale, was distributed to a panel of experts to determine the best advertising locations. Ranked factors were used to create weights for statistical modeling and mapping within a Geographic Information Systems to determine optimal ad locations. The media campaign was evaluated via a telephone survey of randomly selected households.

RESULTS: $\quad$ The survey found locations of new families, high population density, and high percentage of lone parents to be the most important factors for selecting billboard sites. Spatial analysis revealed six areas that ranked highest in our factors. Five billboards, four media posters, and six transit shelters were selected for our advertisements. A population-based telephone survey revealed that $23 \%$ of respondents knew the campaign. Nearly half $(42 \%)$ heard the radio public service announcements, and $9 \%$ saw billboards.

CONCLUSION: Extending primary prevention efforts to the public helps to create a cultural change in the way inconsolable crying, the trigger for AHT, is viewed. With the use of ranked factors and Geographic Information Systems, geographic locations with high visibility and specific risk factors for AHT were identified for targeting the campaign, facilitating the likelihood that our message was reaching the population in greatest need. (J Trauma Acute Care Surg. 2015;79: 748-755. Copyright (C 2015 Wolters Kluwer Health, Inc. All rights reserved.)

KEY WORDS: Abusive head trauma; injury prevention; children and adolescents; Geographic Information Systems.

\begin{abstract}
A busive head trauma (AHT) accounts for more severe injury in infants than any other mechanism and is the leading cause of death from abuse. ${ }^{1,2}$ AHT includes all types of mechanisms of abuse including blunt impact and the shaking of an infant or young child. The shaking, which has also been referred to as shaken baby syndrome (SBS), is a subset of AHT and subjects infants to rapid acceleration, deceleration, and rotational forces. ${ }^{3,4}$ It results in an inflicted traumatic brain injury, characterized by subdural hematomas, diffuse axonal injury, and retinal hemorrhages. ${ }^{4-7}$ Although the term $S B S$ has been used for a number of decades, advances in the understanding of the mechanisms and clinical spectrum of injury associated with AHT have led the American Academy of Pediatrics to recommend the use of the term $A H T{ }^{3}$ so this is how we will refer to inflicted injury to the head and brain throughout the remainder of this article.
\end{abstract}

Submitted: December 30, 2014, Revised: June 30, 2015, Accepted: July 2, 2015 From the Trauma Program (T.C.S., N.G.P., D.D.F), London Health Sciences Centre and Children's Hospital; Departments of Surgery (T.C.S., N.G.P.), and Paediatrics (J.G., D.D.F.), Schulich School of Medicine \& Dentistry, Department of Geography (J.G.), Faculty of Social Sciences, and School of Health Studies (J.G.), Faculty of Health Sciences, University of Western Ontario; Children's Health Research Institute and Lawson Health Research Institute (J.G., D.D.F.) and Centre for Critical Illness Research (D.D.F.), London, Ontario, Canada.

This study was presented at the Trauma Association of Canada annual meeting, April 9-11, 2014, in Montreal, Quebec, Canada.

Address for reprints: Tanya Charyk Stewart, MSc, Trauma Program, Room E1-129, Children's Hospital, LHSC, 800 Commissioners Rd E, London, ON, Canada, N6A 5W9; email: Tanya.CharykStewart@lhsc.on.ca.

DOI: $10.1097 /$ TA.0000000000000828
AHT often results in devastating outcomes with neurologic, cognitive, developmental, and visual impairments for survivors with mortality rates estimated up to $38 \%$ of victims. $^{8-11}$ The monetary costs of abuse are also substantial, with the estimated total medical cost attributable to AHT in the first 4 years after diagnosis to be $\$ 47,952$ (95\% confidence interval, $\$ 40,219-\$ 55,685)$ per child (2012 US dollars). ${ }^{12}$ The total lifetime economic burden of fatal and nonfatal child maltreatment in the United States has been estimated between $\$ 124$ billion and $\$ 585$ billion. ${ }^{13}$ These health and financial costs of AHT support concentrated efforts for its prevention, as AHT is a completely preventable phenomenon.

One such AHT prevention program is the Period of PURPLE Crying (PURPLE). PURPLE is an acronym that stands for the characteristics of infant crying in the first few months of life: Peak of crying, Unexpected, Resists soothing, Pain-like face, Long lasting, Evening and late afternoon. ${ }^{14}$ It was developed by the National Center on Shaken Baby Syndrome (NCSBS), uses positive messages to educate parents about normal infant crying patterns and why inconsolable crying can be frustrating, and provides infant soothing strategies to cope with a crying infant. ${ }^{14,15}$ PURPLE is delivered via a "triple-dose" approach consisting of in-hospital education to parents from registered nurses (RNs) after birth (Dose 1), reinforcement from public health $\mathrm{RNs}$ during postdelivery home visits (Dose 2), and finally, public education through a media campaign (Dose 3 ).${ }^{14}$ This media campaign, the third dose, was developed to reinforce the messages of PURPLE among new parents and to raise awareness among friends, family members, and neighbors who could potentially 
serve as caregivers or provide emotional support to parents of newborns. ${ }^{16}$

With financial constraints and approximately 350 potential billboard and sign locations, it was necessary to target our campaign to ensure it was reaching the population in greatest need of receiving the messages contained in the AHT prevention media campaign. Therefore, the study objectives were to describe novel qualitative and spatial methods developed to target AHT prevention messages and to evaluate the implementation of this media campaign.

\section{PATIENTS AND METHODS}

This study has a mixed-methods research design that incorporated a qualitative survey and quantitative spatial methods to target an AHT prevention media campaign. There is also an evaluative component to this study, in which the reach of the campaign was assessed via a population-based telephone survey. The Health Sciences Research Ethics Board at Western University approved this study.

\section{The Media Campaign}

A media campaign was developed by the NCSBS after a rigorous social marketing process of creating and pretesting media products, based on the Period of PURPLE Crying educational materials. A series of 10 focus groups were conducted to test the PURPLE materials and to identify which messages from the DVD and booklet were most resonant with the participants. Participants were surprised to learn that prolonged infant crying can be completely normal. Based on this and final message testing completed with intercept interviews, the resulting "normalcy" media campaign was developed. ${ }^{16}$ This campaign, which positions infant crying as part of a normal developmental stage rather than caused by caregiver incompetence or an unhealthy infant, was adopted, and an artwork for the print advertisements (Fig. 1) and 60-second radio spots were developed. ${ }^{16}$ The print ads simply stated "Sound familiar?" next to a photo of a crying baby, then "Learn about the Period of PURPLE Crying www.purplecrying.info," in an attempt to drive people to the

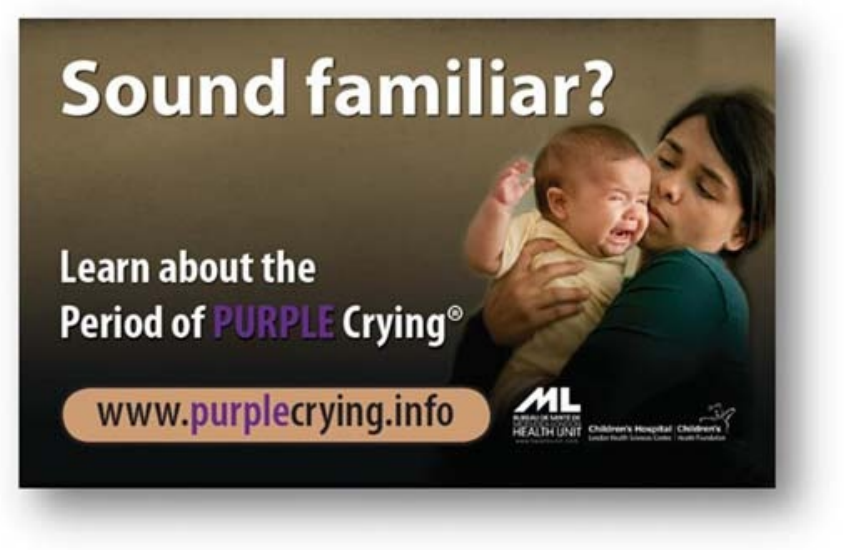

Figure 1. A copy of the Period of PURPLE Crying print ad for the normalcy media campaign.
Web site for more information. The radio spots had the sound of an infant crying, with a voiceover stating that it is normal for a healthy infant to cry for up to 5 hours a day but to never shake a baby. The radio ad ends directing listeners to the Web site, as well. Our available funds allowed for an 8-week campaign that was initiative in May 2010.

\section{Campaign Targeting - Survey and Spatial Analysis}

A survey was undertaken with a panel of experts including pediatricians, RNs, abuse specialists, injury prevention specialists, trauma program manager, medical director, researchers, and communications specialists. The survey focused on the level of importance of factors in AHT and media campaigns, rated on a 7-point Likert scale (from 1 "not important at all" up to 7 "extremely important"). Factors included the location of new families, previous AHT cases, high population density, high traffic volume, low median household income, percentage of lone-parent families, and location of child social services. The factors were transformed and then ranked and weighted using a pairwise comparison method to create criteria maps. The seven maps were then combined using Weighted Linear Combination in Geographic Information Systems (GIS) to produce a single map of the most suitable areas. With the use of coordinates provided from the municipality and sign owners, a GIS shapefile including point locations of every available advertising space (i.e., billboards, core media posters, transit shelters) in London $(\mathrm{n}=349)$ was compared against the combined criteria map to identify which advertisement spaces were located in or within $500 \mathrm{~m}$ of the most suitable areas and to allow us to select preferred locations for AHT prevention advertisements.

\section{Campaign Evaluation}

The media campaign was evaluated via a populationbased telephone survey from May 5 to September 2, 2010. A survey module was developed on the PURPLE media campaign, as part of the Rapid Risk Factor Surveillance System. ${ }^{17}$ Rapid Risk Factor Surveillance System is an ongoing public health telephone survey of 100 randomly selected adults per month who are 18 years or older living in the study region of London and Middlesex County in Ontario, Canada. The survey asks about a variety of health issues, and a module was added to specifically ask about AHT and the prevention media campaign (Appendix A). Descriptive statistics including totals and percentages were calculated on the responses, overall and stratified by age. Pearson $\chi^{2}$ was used to compare proportions by sex. Additional specifics on the analysis by question are presented in Appendix A.

\section{RESULTS}

\section{Campaign Targeting-Survey, Spatial Analysis, Media Site Selection, and Costs}

The AHT and media factors targeting survey had a $100 \%$ response rate $(\mathrm{n}=15 ; 3$ pediatricians, 2 RNs, 1 abuse specialists, 3 injury prevention specialists, 1 trauma program manager, 1 trauma program medical director, 1 researcher, and 
3 communications/media specialists). Based on the responses, the factors were transformed, ranked, and weighted. The resulting criteria weighting scheme based on the level of importance reported in the survey are presented in Table 1, along with data source for the criteria maps that were created for each factor. Two examples of maps for new births and previous AHT cases are presented in Figure $2 A$ and $B$, respectively. The darker areas of the maps have a higher AHT risk and, therefore, more importance for the AHT media campaign. Figure 3 represents the combination of the individual weighted maps for each factor. The spatial analysis revealed six areas throughout the city, which ranked highest in the combination of the AHT and media factors (Fig. 4). Billboard locations throughout the city were overlaid to determine preferred targeted locations for prevention advertisements.

Based on the spatial analysis, the following media outlets were selected: five billboards, four core media posters, and six transit shelters in our six preferred areas. This was supplemented with six bus backs on city buses, two theater screen ads displayed along with other advertisements in a loop before the start of movies; 60 -second radio public service announcements (PSAs); five live 10-minute radio interviews with physicians, RNs and injury prevention specialist on the messages contained within PURPLE educational materials including crying patterns, ways to sooth your baby, as well as dangers of shaking; and 1,000 posters distributed to physician offices, walkin clinics, child care centres, schools, and arenas. Social media including Facebook and Twitter was undertaken by the NCSBS to accompany the local media campaign.

The total costs of the media campaign were CAD $\$ 23,802.07$ (approximately USD \$21,697.43) for an 8-week

TABLE 1. The Criteria Weighting Scheme for Factors Based on the Importance Reported in the Survey

\begin{tabular}{|c|c|c|}
\hline Factor & $\begin{array}{l}\text { Associated } \\
\text { Weight for } \\
\text { Level of } \\
\text { Importance }\end{array}$ & Measure (Data Source) \\
\hline New births/families & $38.2 \%$ & $\begin{array}{l}\text { New births from April } 2008 \text { to } \\
\text { July } 2009 \text { per Statistics Canada } \\
\text { Dissemination Area (LHSC, 2009) }\end{array}$ \\
\hline High lone parenthood & $22.2 \%$ & $\begin{array}{l}\text { Proportion of households headed by } \\
\text { lone parents per Dissemination } \\
\text { Area (Statistics Canada, 2006) }\end{array}$ \\
\hline Population density & $12.0 \%$ & $\begin{array}{l}\text { Population per square kilometers in } \\
\text { Dissemination Area (Statistics } \\
\text { Canada, 2006) }\end{array}$ \\
\hline High traffic volume & $11.6 \%$ & $\begin{array}{l}\text { High traffic volume counts per } \\
\text { kilometer of total roads within } \\
\text { or abutting Dissemination Areas } \\
\text { (City of London, 2010) }\end{array}$ \\
\hline Previous SBS cases & $10.2 \%$ & $\begin{array}{l}\text { Previous SBS cases treated at } \\
\text { Children's Hospital, LHSC, } \\
\text { from } 1991 \text { to } 2009 \text { in Trauma } \\
\text { Registry (LHSC) }\end{array}$ \\
\hline $\begin{array}{l}\text { Low median } \\
\text { household income }\end{array}$ & $5.8 \%$ & $\begin{array}{l}\text { Proportion of households that fall } \\
\text { below Statistics Canada's } \\
\text { Low-Income Cutoff per } \\
\text { Dissemination Area (Statistics } \\
\text { Canada, 2006) }\end{array}$ \\
\hline
\end{tabular}

campaign. This included the costs for customizing and printing the billboards and posters as well as the costs of renting the billboard and poster locations, radio and theater screen time. Not included in this total were the costs associated with developing and testing the print concept, artwork, and PSAs, which were provided by the NCSBS and completed by professors in the School of Journalism and Mass Communication at the University of North Carolina at Chapel Hill, a strategic communication firm and the NCSBS leadership team. ${ }^{16}$

\section{Campaign Evaluation}

A total of 404 adults with telephones were successfully contacted from May 5 to September 2, 2010. Our PURPLE ad campaign module directly followed the other core modules for all health units in Ontario. All 404 participants responded to both our PURPLE module and the core modules asked in the telephone survey. Overall, $23 \%$ of those surveyed reported having seen or heard of the PURPLE media campaign, with no statistical differences in the sex of the respondents (females, $26 \%$ vs. males, $18 \% ; p>0.05$ ) who had seen or heard of the campaign. Highest awareness occurred in the age group of 25 years to 44 years $(43 \%)$. Awareness seemed to decline significantly in older age groups. Of those who had reported having seen or heard of the campaign, the majority ( $42 \%)$ heard of it from the radio; $16 \%$ saw or heard about it at the hospital; and $9 \%$ saw a billboard ad. Other less common sources cited include bus backs, posters, health professional, friends/family, or work. When asked about the main message of the campaign, $36 \%$ of those who reported having seen or heard of the campaign said that the main message had to do with babies crying, and $32 \%$ said it had to do with shaking babies. There were fewer than five respondents who reported visiting the Web site or who planned to go to the Web site for more information. Only $3 \%$ of the respondents were a parent or guardian of an infant at the time of the survey.

\section{DISCUSSION}

Media campaigns are a common tool used in health promotion and for the prevention of disease and injury. ${ }^{18} \mathrm{~A}$ media campaign is the third component of the triple-dose Period of PURPLE Crying AHT prevention program. ${ }^{1,14}$ The goals of this "normalcy" campaign were to both reinforce the PURPLE education to new parents as well as to extend the information regarding infant crying and the dangers of shaking beyond the parents to their friends and family as well as the general public, to bring about a cultural shift in society's understanding and approach to infant crying, the primary trigger for AHT. ${ }^{14,15}$ This is regarded as a catalyst for decreasing the stress many new parents feel when dealing with the inconsolable crying of their infants. ${ }^{14}$

During the past decade, meta-analyses of both health ${ }^{19}$ and drug abuse prevention campaigns ${ }^{20}$ have found an impact on the public's knowledge, attitudes, and even health behavior, although the effect sizes have been relatively small. It has been suggested that further increases to media campaign effectiveness can be maximized by following the design principles of effective campaigns, including conducting formative research, 
the use of theory, and segmenting audiences into subgroups to target based on demographic and risk characteristics. ${ }^{18}$ Fortunately for the users of the PURPLE program, much time and effort were spent by the NCSBS to rigorously develop the media campaign component through multiple focus groups and pretesting the campaign messages with target audiences, based on the PURPLE educational materials. The selected campaign concepts underwent intercept interviews, resulting in further refinement until the final campaign materials were produced. ${ }^{16}$ This process helped ensure the AHT normalcy media campaign's success, with the materials grounded on theory and having undergone extensive formative research. ${ }^{18}$
Message targeting has been reported to be a major factor contributing to the success of previous health media campaigns. $^{21}$ The increased exposure of messages to the target group at most risk can translate into effective change in individual's beliefs and behavior. ${ }^{21}$ To further increase the probability of our campaign success, our team developed a novel qualitative and quantitative method to target the campaign in the regions and population at greatest risk. The use of GIS as a tool to link social, economic, ecologic, and demographic factors is critical for better understanding of injury and its prevention. ${ }^{22}$ The ability to map the distribution of injury and populations at risk as well as spatially analyzing these data

A
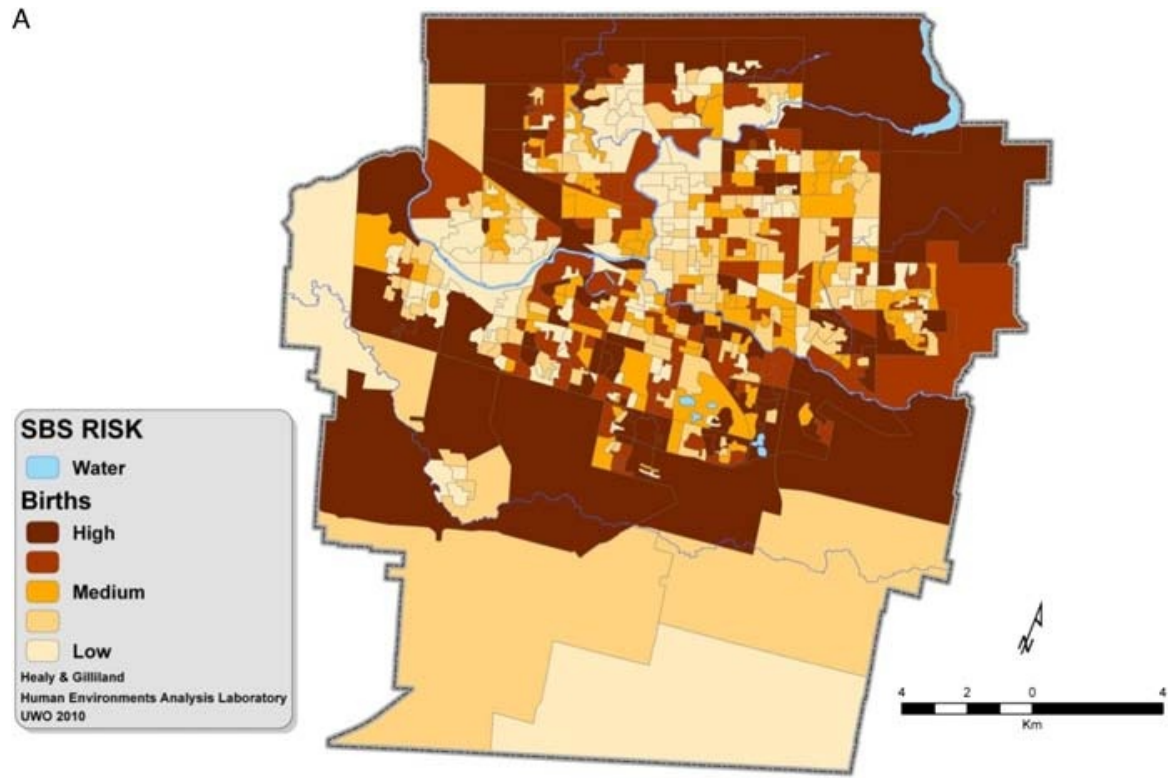

B

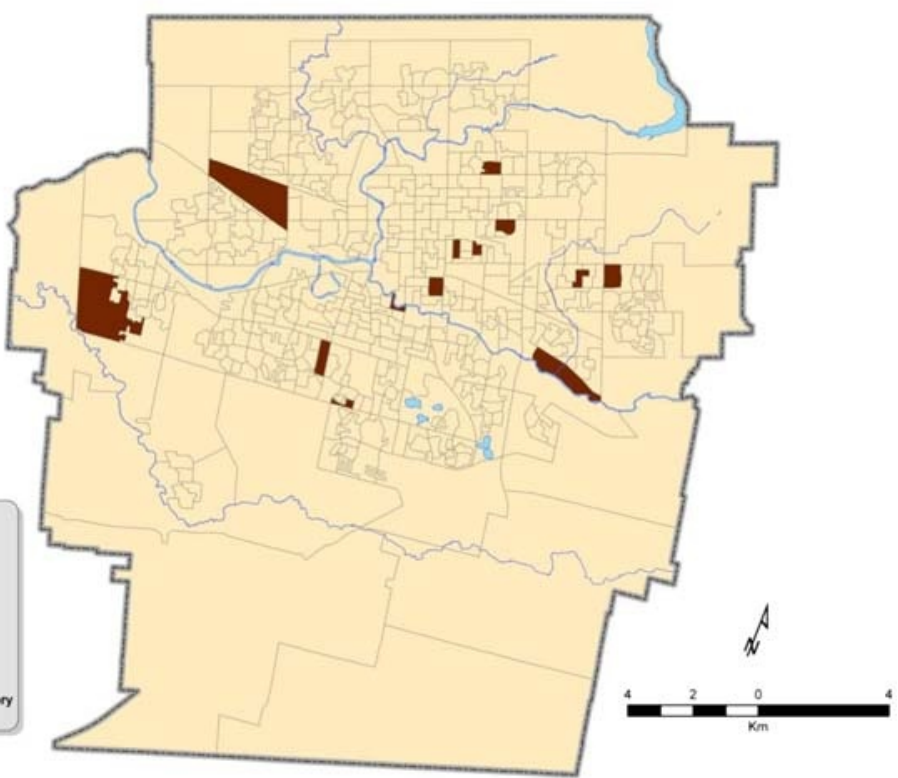

Figure 2. $A$, The map for new births in our region from April 2008 to July 2009 per Statistics Canada Dissemination Area. $B$, The map for previous severely injured SBS cases occurring in our region and treated at the Children's Hospital, LHSC, 1991 to 2009. 


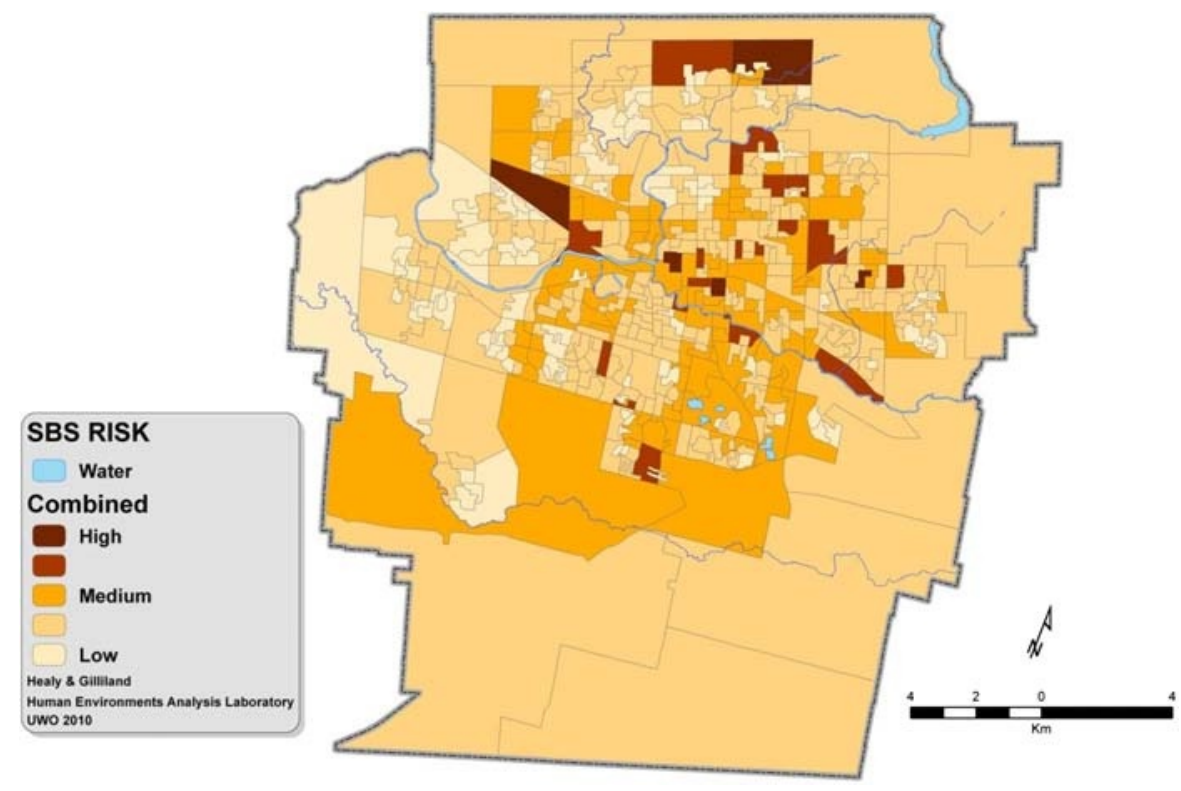

Figure 3. The resulting final map created by combining all maps for each factor using the weighted linear combined method.

can assist in the planning and targeting of interventions. ${ }^{23}$ Indeed, the mapping of the factors deemed to be important to health and media experts for an AHT prevention campaign was used to target the campaign in areas of the city and populations in greatest need of the message. Visually displaying the multivariate relationships between the factors in a combined map and then overlaying the available media outlets allowed for targeted selection of the advertising sites. This process of amalgamating multiple maps of the demographic and other risk factors associated with disease or injury has been suggested to represent a more valid picture of risk than single-factor maps. ${ }^{24}$
Combining sociodemographic and injury data with mapping can be a powerful, evidence-based tool for targeting interventions, including media campaigns. Targeting those individuals at risk allows for increased campaign effectiveness by focusing resources to a segmented, defined population. ${ }^{18}$ Research has shown that targeted, well-executed media campaigns can have moderate effects on the public's knowledge, attitudes, and behaviors, which given the wide range of a mass media campaign, can translate into major public health impact. ${ }^{18}$ In addition, previous research has demonstrated stronger effects for media campaigns that were supplemented with intervention components,

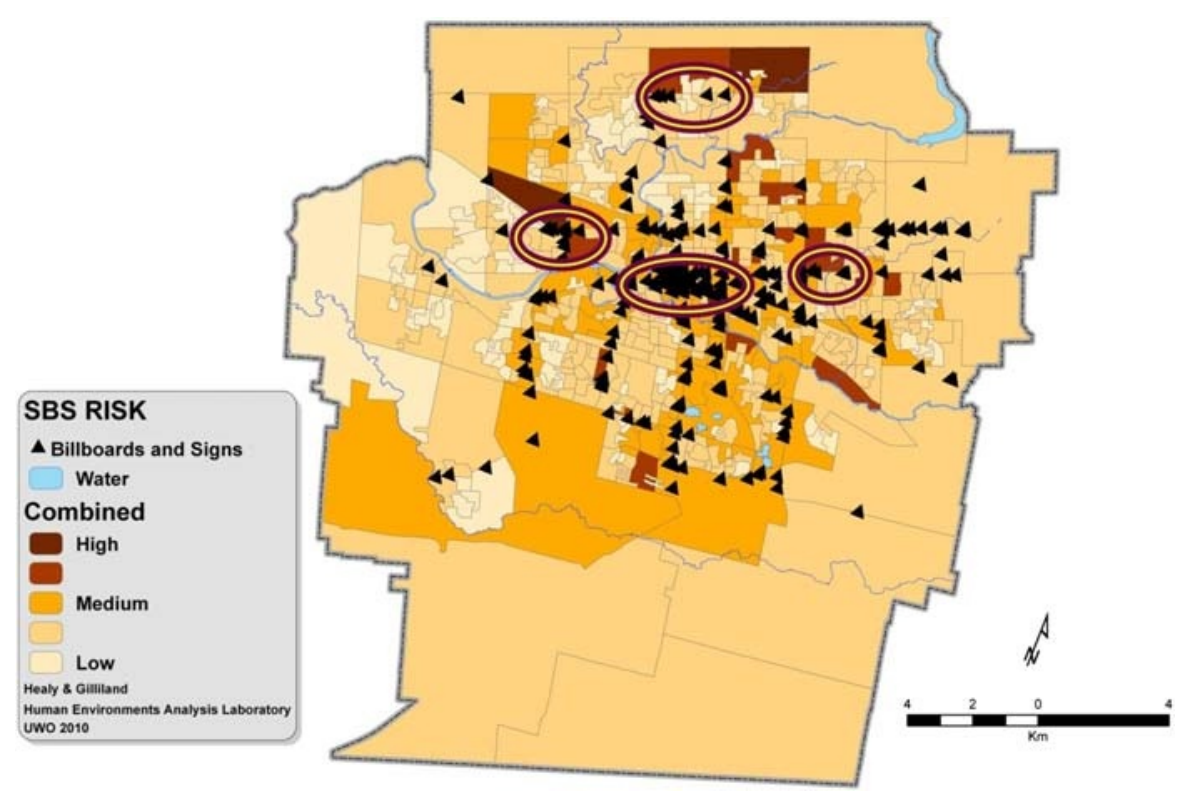

Figure 4. Geographically targeted areas identified after the billboards and sign locations were positioned on map. 
as was the case with our campaign (i.e., Doses 1 and 2 of PURPLE). ${ }^{18,25}$

One of the study limitations was the inability to quantify the effect the PURPLE normalcy campaign had in the targeted population. So, while the campaign was targeted, because of financial constraints, the campaign evaluation was not. Based on the telephone survey, $23 \%$ of all those surveyed and up to $43 \%$ in the age group of 25 years to 44 years old were aware of the media campaign. The overall reach was slightly lower than the reported $36 \%$ to $42 \%$ reach of an average campaign ${ }^{19}$ but likely represents an underestimate because we were not able to limit our evaluation to the few areas of the city that were targeted for the campaign. This broader evaluation area likely accounts for the smaller proportion (9\%) of respondents that remembered seeing the billboard ads in those selected sites. In contrast, the radio PSAs were heard by nearly half of the telephone survey respondents. This suggests that for future media campaigns, funds may be more wisely spent on wider-reaching radio PSAs and social media, as opposed to billboard ads. Overall, the costs of this 8-week campaign were not prohibitive at nearly CAD $\$ 24,000$ (approximately USD $\$ 22,000$ ), as we only purchased billboard and radio airtime and were not required to support the extensive costs of campaign development and testing that was provided by the NCSBS. In fact, our costs represent approximately $10 \%$ of the estimated costs of only one child abuse victim. ${ }^{13}$ Finally, while the ultimate goal of any public awareness campaign, in conjunction with an injury prevention program, is to decrease the incidence of AHT in infants, it was outside the scope of this study's objectives. It is, however, a very important outcome of the overall effectiveness of the triple-dose approach of PURPLE. Because the number of AHT treated at our pediatric trauma centre is low, we need to continue to gather more data on AHT cases to be able to determine the effect of our campaign comparing rates of AHT in the future.

\section{CONCLUSION}

AHT is a devastating intentional injury that often results in poor outcomes for the child and creates a substantial burden for the family, health care system, and society. Extending the primary prevention beyond new parents to the public is intended to create a cultural change in the way crying is viewed and can help decrease the stress on parents when their child is crying inconsolably, the trigger for AHT. Using the sociodemographic and risk factor data along with the GIS, we were able to identify locations within our city with high visibility, a high proportion of new families and specific risk factors for AHT. This allowed us to target our media campaign and increase the likelihood that our message was reaching the population in greatest need.

\section{AUTHORSHIP}

$\overline{\text { All authors have made substantial contributions to the conception, study }}$ design, content, and revision of the manuscript. In addition, T.C.S. performed the literature search, designed the survey, and drafted the initial manuscript. J.G. undertook the mapping and spatial analysis and revised the manuscript. N.G.P. and D.D.F. provided the medical interpretation of the data and results as well as critically reviewed and revised the manuscript. D.D.F. supervised this project. All authors approved the manuscript as it has been submitted.
}

\section{ACKNOWLEDGMENT}

We thank the Children's Health Foundation for their generous financial support of injury prevention programing at Children's Hospital, at London Health Sciences Centre (LHSC). We also thank Denise Polgar and David Tanner, formerly of the Trauma Program, LHSC, as well as Martin Healy of the Human Environments Analysis Lab at Western University for their assistance with program implementation and mapping. We also acknowledge the National Center for Shaken Baby Syndrome for their assistance with the media campaign materials and the MiddlesexLondon Health Unit for their contribution to the campaign evaluation.

\section{DISCLOSURE}

The authors declare no conflicts of interest.

\section{REFERENCES}

1. Charyk Stewart T, Polgar D, Gilliland J, Tanner DA, Girotti MJ, Parry N, Fraser DD. Shaken baby syndrome and a triple-dose strategy for its prevention. J Trauma. 2011;71:1801-1807.

2. Reece RM, Sege R. Childhood head injuries: accidental or inflicted? Arch Pediatr Adolesc Med. 2000;154:11-15.

3. Christian CW, Block R, Committee on Child Abuse and Neglect; American Academy of Pediatrics. Abusive head trauma in infants and children. Pediatrics. 2009;123:1409-1411.

4. Duhaime AC, Christian CW, Rorke LB, Zimmerman RA. Nonaccidental head injury in infants - the "shaken-baby syndrome". N Engl J Med. 1998;338:1822-1829.

5. Duhaime AC, Alario AJ, Lewander WJ, Schut L, Sutton LN, Seidl TS, Nudelman S, Budenz D, Hertle R, Tsiaras W, et al. Head injury in very young children: mechanisms, injury types, and ophthalmologic findings in 100 hospitalized patients younger than 2 years of age. Pediatrics. 1992; 90:179-185.

6. Barr RG, Barr M, Fujiwara T, Conway J, Catherine N, Brant R. Do educational materials change knowledge and behaviour about crying and shaken baby syndrome? A randomized controlled trial. CMAJ. 2009; 180:727-733.

7. Case ME, Graham MA, Handy TC, Jentzen JM, Monteleone JA; National Association of Medical Examiners Ad Hoc Committee on Shaken Baby Syndrome. Position paper on fatal abusive head injuries in infants and young children. Am J Forensic Med Pathol. 2001;22:112-122.

8. King WJ, MacKay M, Sirnick A; Canadian Shaken Baby Study Group. Shaken baby syndrome in Canada: clinical characteristics and outcomes of hospital cases. CMAJ. 2003;168:155-159.

9. Karandikar S, Coles L, Jayawant S, Kemp AM. The neurodevelopmental outcome in infants who have sustained a subdural haemorrhage from nonaccidental head injury. Child Abuse Review. 2004;13:178-187.

10. American Academy of Pediatrics: Committee on Child Abuse and Neglect. Shaken baby syndrome: rotational cranial injuries-technical report. Pediatrics. 2001;108:206-210.

11. Ettaro L, Berger RP, Songer T. Abusive head trauma in young children: characteristics and medical charges in a hospitalized population. Child Abuse Negl. 2004;28:1099-1111.

12. Peterson C, Xu L, Florence C, Parks SE, Miller TR, Barr RG, Barr M, Steinbeigle R. The medical cost of abusive head trauma in the United States. Pediatrics. 2014;134:91-99.

13. Fang X, Brown DS, Florence CS, Mercy JA. The economic burden of child maltreatment in the United States and implications for prevention. Child Abuse Negl. 2012;36:156-165.

14. Reece RM, Dias MS, Barr M, Russell BS, Barr RG, Runyan DK. White paper shaken baby syndrome/abusive head trauma prevention. 2010:1-10. Available at: http://dontshake.org/pdf/WhitePaper_SBS_AHT_Evidenced_ Based_Prevention_12-21-10.pdf. Accessed September 19, 2015

15. Barr RG, Rivara FP, Barr M, Cummings P, Taylor J, Lengua LJ, Meredith-Benitz E. Effectiveness of educational materials designed to change knowledge and behaviors regarding crying and shaken-baby syndrome in mothers of newborns: a randomized, controlled trial. Pediatrics. 2009;123:972-980. 
16. Hennink-Kaminski H, Dougall EK. Tailoring hospital education materials for the period of PURPLE crying: keeping babies safe in North Carolina Media Campaign. Social Marketing Quarterly. 2009;15:49-64.

17. Ontario Ministry of Health and Long-Term Care. Rapid Risk Factor Surveillance System. 2015. Available at: http://www.rrfss.ca/. Accessed June 1, 2015.

18. Noar SM. A 10-year retrospective of research in health mass media campaigns: where do we go from here? J Health Commun. 2006;11:21-42.

19. Snyder LB, Hamilton MA. A meta-analysis of U.S. health campaign effects on behavior: emphasize enforcement, exposure, and new information, and beware the secular trend. In: Hornik RC, ed. Public Health Communication: Evidence for Behavior Change. Mahwah, NJ: Lawrence Erlbaum; 2002:357-384.

20. Derzon JH, Lipsey MW. A meta-analysis of the effectiveness of masscommunication for changing substance-use knowledge, attitudes, and behavior. In: Crano WD, Burgoon M, eds. Mass Media and Drug Prevention: Classic and Contemporary Theories and Research. Mahwah, NJ: Erlbaum, 2002: 231-258.

21. Zimmerman RS, Palmgreen PM, Noar SM, Lustria ML, Lu HY, Lee Horosewski M. Effects of a televised two-city safer sex mass media campaign targeting high sensation-seeking and impulsive decision-making young adults. Health Educ Behav. 2007;34:810-826.

22. Cusimano MD, Chipman M, Glazier RH, Rinner C, Marshall SP Geomatics in injury prevention: the science, the potential and the limitations. Inj Prev. 2007;13:51-56.

23. WHO. Geographic Information Systems (GIS). Wkly Epidemiol Rec 1999; 74:281-288.

24. Parrott R, Hopfer S, Ghetian C, Lengerich E. Mapping as a visual health communication tool: promises and dilemmas. Health Commun. 2007; 22:13-24.

25. Flora JA, Maibach EW, Maccoby N. The role of media across four levels of health promotion intervention. Annu Rev Public Health. 1989;10:181-201.

\section{APPENDIX A.}

\section{THE PERIOD OF PURPLE CRYING MODULE QUESTIONS}

\section{Question 1}

Now some questions about an advertising campaign on infants younger than 1 year.

First, do you now or expect in the next few months to spend time with an infant on a regular basis?

Interviewer: If required, regular basis means about once a month or more frequently.

Response options

1 Yes

5 No

d Don't know

$r$ Refused

\section{Question 2}

Are you currently a parent or a guardian of an infant?

Response options

1 Yes

5 No

d Don't know

$r$ Refused

Analysis issues: Only asked of those who were spending or were expecting to spend time with an infant on a regular basis or refused to answer that question (Question $1=1$ or Question 1r).

\section{Question 3}

Did you receive information, such as a booklet or video for the Period of PURPLE Crying program, for example, at a hospital or from public health?

Interviewer: If required, the Period of PURPLE Crying education was delivered to new parents while in the hospital by a midwife or by a public health nurse at home and included a booklet and a DVD to keep.

Response options

1 Yes

5 No

d Don't know

$r$ Refused

Analysis issues: Only asked of those who were a parent or a guardian of an infant (Question 2=1).

\section{QUESTION 4:}

Have you seen or heard of the Period of PURPLE Crying ad campaign?

Response options

1 Yes

5 No

d Don't know

$r$ Refused

\section{Question 5}

How did you see or hear about it?

Interviewer: Do not read list. Enter 1 to all that apply. Probe once with "Are there any others?"

Response options

1 Billboard

2 Radio

$3 \mathrm{TV}$

4 Bus backs

5 Poster

6 Hospital

7 Friend/family

8 Professional (MD, RN, midwife, trauma program, etc.)

9 Other, specify:

d Don't know

$r$ Refused

Analysis issues: - Only asked of those who had seen or heard of the media campaign (Question $4=1$ ). - Text file for "other" response option requires separate analysis.

\section{Question 6}

What was the main message of the campaign?

Interviewer: Do not read list. If respondent comes up with more than one message, enter the one they mention first.

Response options

1 Any mention of babies crying 
2 Any mention of shaking babies

3 To visit the Web site

4 Other, specify:

d Don't know

r Refused

Analysis issues: - Only asked of those who had seen or heard of the media campaign (Question $4=1$ ). $・$ Text file for "other" response option requires separate analysis

\section{Question 7}

Were there any other messages in this campaign?

Interviewer: Do not read list. Enter 1 to all that apply. Probe once with "Were there any others?" If R mentioned two or more messages in Question 6, check those not selected as the main message on Question 6 here.

Response options

0 No other message perceived

1 Any mention of babies crying

2 Any mention of shaking babies

3 To visit the Web site

4 Other, specify:

d Don't know

$r$ Refused

Analysis issues: - Only asked of those who had seen or heard of the media campaign (Question $4=1$ ) and had indicated that they knew what the main message was (Question $7=1,2,3$, or 4$)$. Text file for "other" response option requires separate analysis.

\section{Question 8}

Did you go to the purplecrying.info Web site for more information?

Response options

1 Yes

5 No

d Don't know

r Refused
Analysis issues: - Only asked of those who had seen or heard of the media campaign (Question $4=1$ ).

\section{Question 9}

Do you plan to?

Response options

1 Yes

5 No

d Don't know

r Refused

Analysis issues: Only asked of those who had seen or heard of the media campaign (Question $4=1$ ) and who were spending or were expecting to spend time with an infant on a regular basis (Question $1=1$ ).

\section{Question 10} Web site?

Could you tell us why you are not planning to go to the

Interviewer: Do not read list. Enter 1 to all that apply. Probe once with "Are there any other reasons?"

Response options

1 Lack of time

2 Don't remember the actual Web site

3 Don't know about a Web site

4 Not interested

5 I already know enough

6 Other, specify:

d Don't know

$r$ Refused

Analysis issues: Only asked of those who had seen or heard of the media campaign (Question $4=1$ ) and who were spending or were expecting to spend time with an infant on a regular basis (Question $1=1$ ). 